\title{
Environmental Factors Influencing the Distribution of Oncomelania hupensis in Central Region, China
}

\author{
Yi Yuan ${ }^{1 *}$, Bianrong Chang ${ }^{2}$, Juan Qiu ${ }^{3}$, Kequn Liü ${ }^{4}$ Xinjian $\mathrm{Xu}^{1}$ and Rendong $\mathrm{Li}^{3}$ \\ ${ }^{1}$ Institute of Schistosomiasis Control, Hubei Center for Disease Control and Prevention, Wuhan 430079, China \\ ${ }^{2}$ Tianjin Agricultural University, Tianjin 300384, China
}

${ }^{3}$ Key Laboratory of Monitoring and Estimate for Environment and Disaster of Hubei Province, Institute of Geodesy and Geophysics, Chinese Academy of Sciences, Wuhan 430077, China

${ }^{4}$ Wuhan Regional Climate Center, Wuhan 430074, China

"Corresponding author: Yi Yuan, Institute of Schistosomiasis Control, Hubei Center for Disease Control and Prevention, Wuhan 430079, China; Tel: 13907184966; Email: yuanyi5555@foxmail.com

Received date: May 18, 2018; Accepted date: July 25, 2018; Published date: August 13, 2018

Copyright: @ 2018 Yuan, et al. This is an open-access article distributed under the terms of the Creative Commons Attribution License; which permits unrestricted use; distribution; and reproduction in any medium; provided the original author and source are credited.

\begin{abstract}
Schistosomiasis, caused by the snail-borne parasite Schistosoma japonicum, remains highly prevalent in Hubei, China, especially the central region (Jianghan Plain). Because the control of $S$. japonica primarily depends on the rapid discovery and elimination of its intermediate host Oncomelania hupensis snails, the spatio-temporal distribution of snails and the environmental factors influencing it warrant clarification. We used geographic information system technology to investigate the spatial dynamics of snail distribution in Jianghan Plain from 2008 to 2012. A generalized linear-mixed model, with time as a random effect, was applied to characterize the relationship between snail density at the village level and the associated environmental factors. The percentage of villages in which the frequency of areas with $<50 \%$ snail occurrence was $71.74-82.67 \%$, which was much higher than that for villages where snail occurrence was $>50 \%$ (17.33-28.26\%). Precipitation, daylight hours, land surface temperatures, wetness index, and proportion of silt were positively associated with snail density, with precipitation having the greatest effect. Normalized difference vegetation index and elevation were negatively associated with snail density. Our findings can be used as a theoretical basis to develop models predicting outbreaks of snail occurrence in the Jianghan Plain and for preventing and controlling schistosomiasis.
\end{abstract}

Keywords: Schistosoma japonicum; Oncomelania hupensis; Directional distribution analysis; Environmental factors; Generalized linear-mixed model; Jianghan plain

\section{Introduction}

Schistosomiasis japonica is a snail-borne parasitic disease with a documented history of over 2,100 years in China. This disease presents a major threat to human health and negatively affects socioeconomic development [1-4]. The snail Oncomelania hupensis is the sole intermediary host of Schistosoma japonicum, and it has a distribution endemic to the Yangtze River basin, including seven provinces in central China. These provinces include Hubei, Hunan, Jiangxi, Anhui, Jiangsu, Sichuan, and Yunnan, with the latter two occurring in mountainous regions $[1,5]$. The survival and reproduction of snails, as well as their distribution, are strongly associated with various environmental factors in their habitats. Such factors include temperature (e.g., air temperature, land surface temperature, and daylight hours), vegetation (e.g., type, height, and coverage), hydrology (e.g., precipitation, water level, and water table), soil (e.g., soil silt granules, humidity, and $\mathrm{pH}$ ), and elevation [6-13]. Snail habitats are associated with the diversity of water bodies, water networks, and hill types in the endemic region. The middle reaches of the Yangtze River have the severest epidemics of schistosomiasis in China. Many studies have reported the distribution of Oncomelania snails in the lakes and marshlands of Hunan, Jiangxi, Anhui, and Jiangsu provinces $[8,10,14,15]$. However, these studies only assessed snail distribution in relation to one or a few environmental factors, such as soil humidity or vegetation density, neglecting the effect of geographical and environmental factors, e.g., air temperature, precipitation, elevation, and soil silt granules. Previous analyses of the relationship between environmental factors and snail distribution tended to use simple superposition analyses, statistical analyses, and linear regression analyses, rather than considering spatio-temporal data autocorrelation and the variation characteristics of the space model to evaluate variation.

Thus, the current study evaluated the spatio-temporal dynamics of the occurrence rate of Oncomelania snails at the village level throughout the Jianghan Plain and assessed how these dynamics are associated with environmental factors. Specifically, we used the normalized difference vegetation index (NDVI), wetness index (WI), and land surface temperatures (LSTs) at high spatial resolutions ( $30 \mathrm{~m}$ ) over consecutive years as substitutes for vegetation cover, soil humidity, and temperature, respectively. By conducting multi-factor comprehensive analysis, we attempted to quantify the relationship between changes in snail dynamics (density and distribution) and environmental factors. We developed an optimal GLMM by using a space-time distribution model to evaluate snail density and distribution, as well as the risk of snails diffusing to other areas. In this model, year was used as a random effect based on the time-series data of snails at the village level in Gong'an County from 2008 to 2012. Our analyses are expected to provide technical support for the accurate and quick planning of snail control measures and countermeasures by the health administration department. Therefore, the findings of this study will be of value at a national scale. 
Citation: Yuan Y, Chang B, Qiu J, Liu K, Xu X, et al. (2018) Environmental Factors Influencing the Distribution of Oncomelania hupensis in Central Region, China. J Trop Dis 6: 270. doi: 10.4172/2329-891X.1000270

Page 2 of 8

\section{Materials and Methods}

\section{Study area}

Hubei province is located in the middle of central China, in the middle reaches of the Yangtze River and north part of Dongting Lake. The geographical coordinates of the site are $108^{\circ} 21^{\prime} 42^{\prime \prime}-116^{\circ} 07^{\prime} 50^{\prime \prime} \mathrm{E}$ and $29^{\circ} 01^{\prime} 53^{\prime \prime}-33^{\circ} 16^{\prime} 47^{\prime \prime} \mathrm{N}$. The area is situated in the northern part of a temperate subtropical zone. The average annual precipitation range of the last 10 years in this area was 1100-1300 mm. Hubei Province has had the highest incidence of schistosomiasis in the country for the last 10 years. Thirty-three percent of patients with schistosomiasis in China were documented in Hubei Province alone, and 90\% of snail-infested areas inside embankments occurred in this province in 2012. The Jianghan Plain, also in the middle reaches of the Yangtze River, is in the central and southern part of Hubei Province. The plain encompasses 50 counties and cities, among which 40 counties and cities fall in the endemic area of schistosomiasis (Jing'zhou, Sha'shi, Jiang'ling, Gong'an, Jian'li, Shi'shou, Hong'hu, Song'zi, Xian'tao, Qian'jiang, Tia'men, Jiang'an Han'yang, Wu'chang, Qing'shan, Hong'shan, Dong'xihu, Han'nan, Jiang'xia, Cai'dian, Huang'pi, Xin'zhou, Xiao'nan, Han'chuan, Ying'cheng, Yun'meng, Zhong'xiang, Dong'bao, Duodao, Qu'jialing, Jing'shan, Sha'yang, Yuan'an, Yidu, Dang'yang, Zhi'jiang, Yi'ling, Wu'jiagang, Dian'jun, and Xiao'ting; Figure 1), and covers a terrestrial area of about 46,000 square kilometers. Seventy-percent of patients and snail-infested areas in Hubei Province occur in the Jianghan Plain, making it one of the worst affected areas in China. Ethical approval was not required as the study used data provided by the project cooperation of National Science and Technology Support Plan (2003-2008).

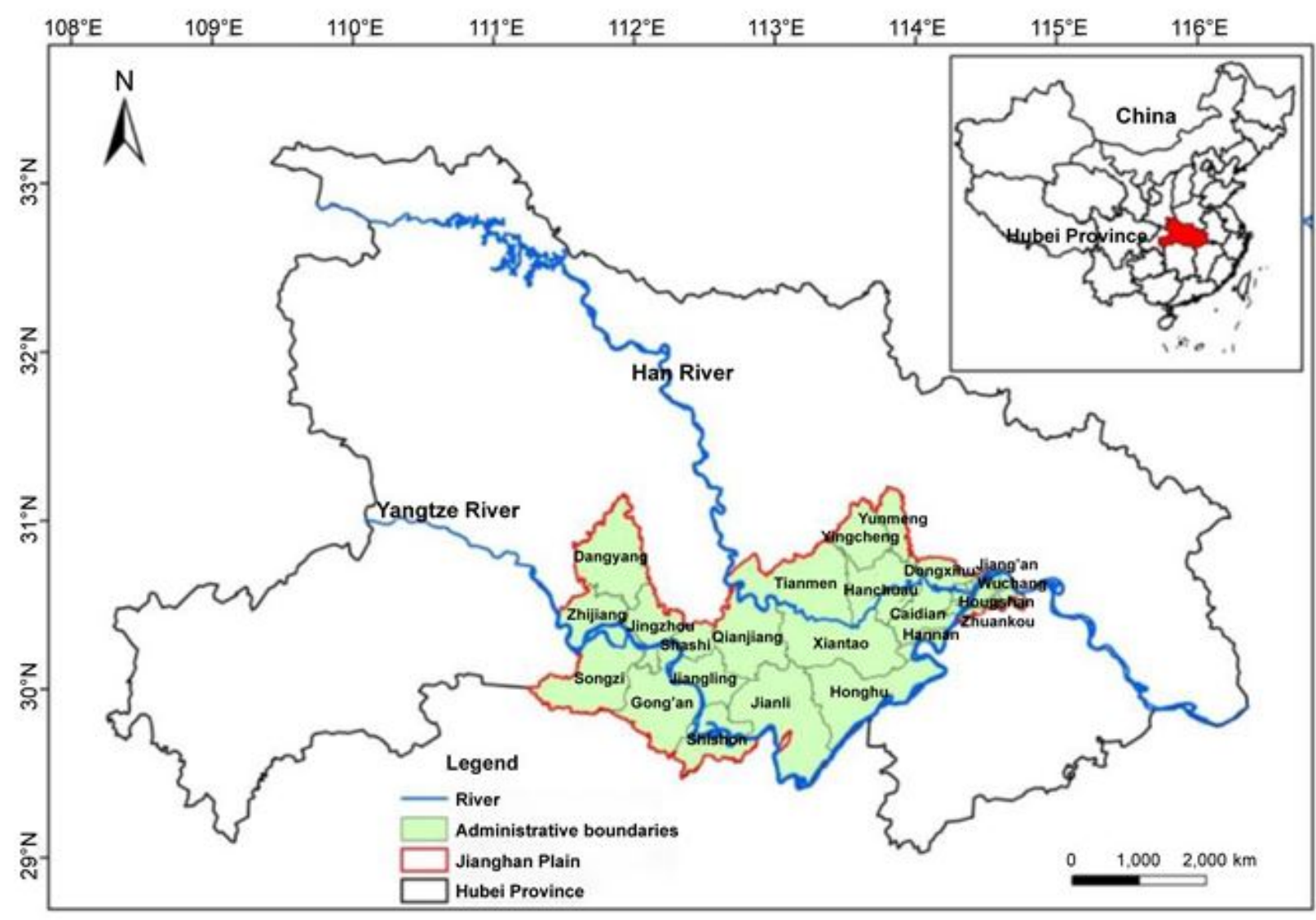

Figure 1: Location of the Jianghan Plain, Hubei Province, China.

\section{Data sources}

Snail data: Snail data at the village level for 2008 to 2013 were provided by the National Science and Technology Support Plan. The collected data included snail occurrence rate (OR) and snail distribution areas at the village level in the Jianghan Plain, snail density at the village level in Gongan County during 2008-2012, and snail distribution areas at the county level in the Jianghan Plain for 2013. These data were originally collected by the local authorities involved in schistosomiasis control.
Field investigations of snail density data were conducted. Systematic sampling was conducted each year from March to May in schistosomiasis endemic villages of Gongan County. During the field investigation, several square frames were randomly specified in each schistosomiasis endemic village, and the number of snails per frame was recorded. The sampling area of each square frame was approximately $0.11 \mathrm{~m} 2$. The number of square frames in Gongan County was $398,743,669,086,621,511,702,475$, and 581,084 in 2008 , 2009, 2010, 2011, and 2012, respectively. The OR and mean snail 
Page 3 of 8

density at the village level were calculated by using formulae (1) and (2), respectively.

$$
O R=A_{1} / A_{2}(1)
$$

Where, OR is the rate of occurrence of snail-infested areas in the investigated village; $A_{1}$ is the area with snails in the investigated village; and $\mathrm{A}_{2}$ is the area investigated in the village.

$$
D=N_{1} / N_{2}(2)
$$

Where, $D$ is the mean snail density; $N_{1}$ is the total number of snails collected in one schistosomiasis endemic village; and N2 is the total number of sampling frames in this village.

\section{Environmental data}

The time-series data of various environmental factors were collected at high spatial resolution $(30 \mathrm{~m})$ consecutively, including the NDVI, WI, and LST, which were used as substitutes for vegetation cover, soil humidity, and temperature, respectively.

Meteorological data (monthly daylight hours and precipitation from March to May) were provided by the Meteorological Bureau of Hubei Province. These two village-level meteorological parameters were obtained by using an inverse distance weighting method in ArcGIS 10.1 (ESRI Inc., Redlands, CA, USA) based on 16 meteorological stations in the Jianghan Plain [16].

Landsat TM/ETM images were selected to extract remote sensing indices, including NDVI, WI, and LST, because these images are open access and are available at high spatial resolution. The Landsat data (path: 124, row: 39) collected from March to May were acquired from the United States Geological Survey [17]. To obtain actual reflectivity data of the land surface, we processed the Landsat data through radiometric calibration and atmospheric correction. The NDVI tool and tasseled-cap transformation were employed to derive NDVI and WI, respectively. The infrared band was selected to retrieve LST by using the radioactive transfer equation $[18,19]$. Because the resolutions of the infrared band for Landsat TM and Landsat ETM are $120 \mathrm{~m}$ and $60 \mathrm{~m}$, respectively, the LST-retrieved images were resized at a spatial resolution of $30 \mathrm{~m}$ for consistency. These operations were carried out in ENVI 5.1.

The meteorological and environmental factors analysed in this study were consistent with those observed during snail sampling. These factors are presented as the average values between March and May of each year for each village. The proportion of clay, sand, and silt, which represent the soil texture, was provided by the Institute of Remote Sensing and Digital Earth, Chinese Academy of Sciences. Elevation data at a spatial resolution of $30 \mathrm{~m}$ using a digital elevation model (ASTER GDEM V2) were downloaded from the International Scientific and Technical Data Mirror Site, Computer Network Information Center, Chinese Academy of Sciences. The minimum distance of the center of each administrative village to the nearest water source was calculated by using the "Near" tool in ArcGIS10.1 (ESRI Inc.).

\section{Methods}

\section{Descriptive analysis}

The spatial distribution of areas with snails at the village level in the Jianghan Plain from 2008 to 2012 was displayed visually using the ArcGIS 10.1 mapping technique (ESRI Inc.).

\section{Generalized Linear Mixed Models}

Generalized linear mixed models (GLMMs) are used extensively in infectious disease epidemiology to analyze various types of data, including repeated measures data [20]. Snail density in each village over consecutive years within a changing geographical environment constitutes longitudinal data of the OR repeated measures. In contrast to traditional models, such as standard linear regression models (LMs) and generalized linear models (GLMs), GLMMs allow the modeling of longitudinal non-normally distributed data. Therefore, GLMMs were used to identify the environmental factors regulating snail distribution (IBM SPSS Statistics 20). These GLMMs are presented as follows $[21,22]$ :

$$
\mathrm{Y}=\mu+\varepsilon, \mu=\mathrm{g}^{-1}(\eta)=\mathrm{g}-1(\mathrm{X} \beta+\mathrm{Z} \gamma)(3)
$$

where $\mathrm{Y}$ is a response variable of length $n ; \mathrm{X}$ and $\mathrm{Z}$ are $n \times p$ and $n \times$ $q$ matrices of explanatory variables associated with fixed and random effects, respectively; $\beta$ and $\gamma$ are the vectors of fixed and random effect parameters, respectively; $g(\eta)$ is a monotonic differentiable link function; $\mathrm{g}^{-1}(\eta)$ is the inverse function of $\mathrm{g}(\eta) ; \gamma$ is distributed as $N(0, G)$ (normal with mean 0 and covariance matrix G); and $\varepsilon$ is the vector of the errors.

Before our analysis, variables with high collinearity were removed, and the results were verified by validating variance inflation factors (VIFs). VIFs of $<10$ correspond to low collinearity [23]. We selected different combinations of error distributions (gamma or normal distribution) of snail density and link functions (log or identity) as components of GLMMs to fit the snail density data. Information criteria (namely, Akaike information criterion corrected (AICC) and Bayesian information criterion (BIC)) were used to compare the goodness-of-fit of models with the same error distributions and to select the optimum model $[24,25]$. When different error distributions were used for the GLMMs, scatter plots of predictions versus observations were applied to compare the goodness fit of the resulting model. If the regression coefficients of the variables were statistically significant $(\mathrm{p}<0.05)$, these variables were confirmed to influence snail density. All the variables were standardized using Z-score transformation to compare their effects on snail distribution.

\section{Results}

\section{Spatio-temporal variation in the rates of snail occurrence}

The distribution of occurrence rates of snail-infested areas at the village level in the Jianghan Plain from 2008 to 2012 is shown in Figure 2 . The occurrence rates differed with time and significantly varied according to spatio-temporal distributions. Overall, villages with higher occurrence rates of snail-infested areas exhibited a spatial distribution pattern of moving east to west gradually, and the number of the villages with higher occurrence rates of snail-containing areas decreased in 2008-2012. Over the five-year period, the villages in the southern part of Xian'tao City and the western part of Shishou City showed higher occurrence rates. From 2008 to 2010, the distribution pattern of the villages in the northern part of Han'chuan City, which had higher occurrence rates of snail-infested areas, changed into dispersion distribution. However, there was a significant increase in the number of areas with high snail occurrence rates in the western part of Qian'jiang City, Song'zi City, Sha'shi District, and Jiang'ling County. In 2011, the number of villages that had the highest occurrence rates of snail-containing areas significantly declined throughout the study area, 
Citation: Yuan Y, Chang B, Qiu J, Liu K, Xu X, et al. (2018) Environmental Factors Influencing the Distribution of Oncomelania hupensis in Central Region, China. J Trop Dis 6: 270 6: 270. doi:10.4172/2329-891X.1000270

Page 4 of 8

but the rates again increased in 2012. Areas harboring snails showed a greater decrease in 2012 than in the previous three years.

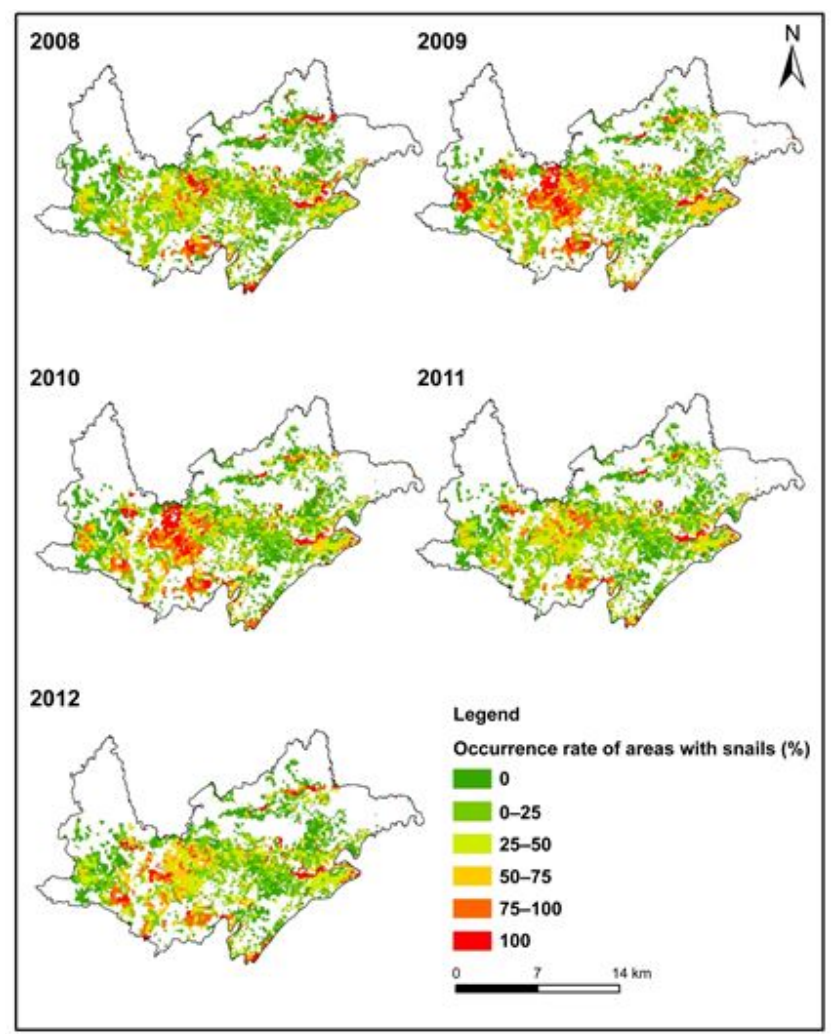

Figure 2: Occurrence rates of snail-infested areas at the village level in the Jianghan Plain from 2008 to 2012.

Table 1 lists the percentage of villages with six grades (each of 25\%) of occurrence rates of snail-containing areas in the Jianghan Plain from 2008 to 2012 . The percentage of villages with $>50 \%$ occurrence rates were divided into three grades: $50-75 \%, 75-100 \%$, and $100 \%$, which continued to increase from 2009 to 2010. In 2011, the percentages of the three grades decreased significantly, but again increased in 2012. In contrast, the percentage variation of villages with $<50 \%$ of occurrence rates of areas with snails (including $0 \%, 1-25 \%$, and $25-50 \%$ ) decreased from 2009 to 2010. In 2011, the number of areas with snail occurrence increased significantly, but again decreased in 2012. During the research period, the percentage of villages with areas where snail occurrence was $0 \%$ was $33.44-37.55 \%$. The percentage of villages with $<50 \%$ occurrence rates of snail-containing areas ranged between $71.74 \%$ and $82.67 \%$, which was much higher than that the percentage of villages with $>50 \%$ occurrence rates of snail-containing areas (17.33-28.26\%).

\begin{tabular}{|l|l|l|l|l|l|}
\hline $\begin{array}{l}\text { Occurrence rate of } \\
\text { snail-containing areas } \\
(\%)\end{array}$ & $\mathbf{2 0 0 8}$ & $\mathbf{2 0 0 9}$ & $\mathbf{2 0 1 0}$ & $\mathbf{2 0 1 1}$ & $\mathbf{2 0 1 2}$ \\
\hline 0 & 37.55 & 33.44 & 34.53 & 33.8 & 34.55 \\
\hline$(1-25)$ & 29.93 & 24.7 & 23.8 & 29.87 & 26.38 \\
\hline$(25-50)$ & 14.44 & 13.95 & 13.41 & 19 & 17.55 \\
\hline Subtotal <50 & 81.92 & 72.09 & 71.74 & 82.67 & 78.48 \\
\hline$(50-75)$ & 7.52 & 9.41 & 9.56 & 8.58 & 9.88 \\
\hline$(75-100)$ & 5.36 & 10.5 & 10.9 & 5.52 & 7.26 \\
\hline 100 & 5.2 & 8 & 7.8 & 3.23 & 4.38 \\
\hline Subtotal $>50$ & 18.08 & 27.91 & 28.26 & 17.33 & 21.52 \\
\hline Total & 100 & 100 & 100 & 100 & 100 \\
\hline
\end{tabular}

Table 1: Percentage of villages with different occurrence rates of snailcontaining areas in the Jianghan Plain from 2008 to 2012.

\section{Snail density in Gong'an county}

Figure 3 and Table 2 present the spatial distribution of snail density and the associated descriptive statistics at the village level in Gongan County from 2008 to 2012. Snails were detected in about $60 \%$ of the villages. Snail density ranged from 0 to about $2 / 0.11 \mathrm{~m} 2$. Only some villages had high snail densities $\left(>3 / 0.11 \mathrm{~m}^{2}\right)$ in 2009,2010 , and 2012 , and were widely dispersed within villages (i.e., not concentrated in any one area). In 2008, 2009, and 2010, the minimum snail density was $0.01 / 0.11 \mathrm{~m}^{2}$ overall; however, the maximum density increased over the three years. The density of snails fluctuated the most in 2010, ranging between $0.01 / 0.11 \mathrm{~m}^{2}$ and $7.0 / 0.11 \mathrm{~m}^{2}$. Hence, the mean, median, and variance of snail density increased significantly with each successive year. In 2011 and 2012, the minimum overall snail density was $0 / 0.11 \mathrm{~m}^{2}$. The range of snail density was smaller in 2011 , with a maximum density of $2.81 / 0.11 \mathrm{~m}^{2}$. However, the maximum snail density increased again in 2012, reaching 4.14/0.11 $\mathrm{m}^{2}$. Correspondingly, the mean, median, and variance of snail density decreased significantly, with an increment in the maximum density over this two-year period compared with the previous three-year period. In addition, the values of skewness and kurtosis exceeded 1, suggesting that snail density was not normally distributed.

\begin{tabular}{|l|l|l|l|l|l|l|}
\hline Year & Range & Mean & Median & Variance & Skewness & Kurtosis \\
\hline 2008 & $0.01 \sim 2.21$ & 0.36 & 0.28 & 0.12 & 2.26 & 6.76 \\
\hline 2009 & $0.01 \sim 3.21$ & 0.72 & 0.46 & 0.47 & 1.41 & 1.56 \\
\hline 2010 & $0.01 \sim 7.0$ & 0.88 & 0.53 & 1.08 & 2.99 & 11.58 \\
\hline 2011 & $0 \sim 2.81$ & 0.56 & 0.36 & 0.29 & 1.39 & 1.67 \\
\hline
\end{tabular}


Citation: Yuan Y, Chang B, Qiu J, Liu K, Xu X, et al. (2018) Environmental Factors Influencing the Distribution of Oncomelania hupensis in Central Region, China. J Trop Dis 6: 270. doi: 10.4172/2329-891X.1000270

Page 5 of 8

\begin{tabular}{|l|l|l|l|l|l|l|}
\hline 2012 & $0 \sim 4.14$ & 0.49 & 0.23 & 0.45 & 2.53 & 7.86 \\
\hline
\end{tabular}

Table 2: Descriptive statistics of snail density in Gongan County.

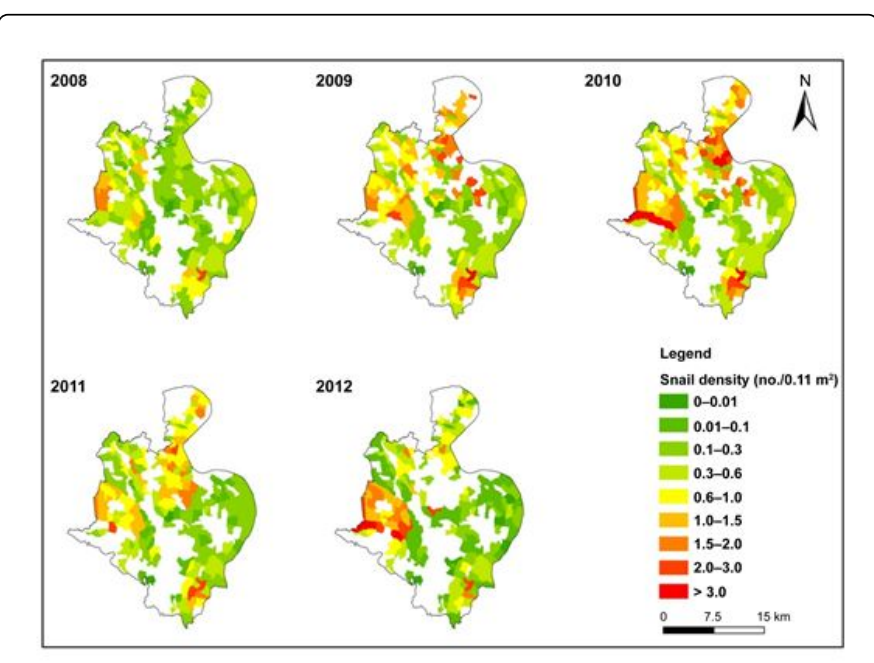

Figure 3: Spatial distribution of snail density at the village level in Gong'an County from 2008 to 2012.

\section{Influencing environmental factor}

Collinearity analysis confirmed that the proportion of clay and sand in the soil was excluded at VIFs of $>10$. Eight other environmental factors were involved in the model, with year as the random effect. Table 3 presents the fitting results of the GLMMs, in which different error distributions and link functions were combined. These models were statistically significant $(p<0.001)$ and might indicate the factors influencing snail density. Models with the intercept and year as random effects (i.e., models 1,3 and 5) provided smaller values of information criteria than the corresponding models that only used the intercept as a random effect (i.e., models 2,4 and 6). When using models 3 and 5 with "Normal" as the error distribution, the former yielded smaller AICC and BIC values than the latter. Model 1 was compared with model 3 by using the predicted value in the observed plots. Figures 4 (a) and (b), respectively, presented the predicted value in the observed plots of model 1 (a gamma distribution and a logarithmic link function) and model 3 (a normal distribution and an identity link function). The findings in these figures support those presented in Table 4 . The points in model 1 were much closer to $45^{\circ}$ than model 3; therefore, model 1 is the most appropriate model out of all analysed models in this study.

\begin{tabular}{|l|l|l|l|l|l|l|}
\hline $\begin{array}{l}\text { Model } \\
\text { S }\end{array}$ & $\begin{array}{l}\text { Error } \\
\text { distributio } \\
\mathbf{n}\end{array}$ & $\begin{array}{l}\text { Link } \\
\text { functio } \\
\mathbf{n}\end{array}$ & AICC & BIC & $\begin{array}{l}\mathbf{p}- \\
\text { valu } \\
\mathbf{e}\end{array}$ & Random effect1 \\
\hline $\begin{array}{l}\text { Model } \\
1\end{array}$ & Gamma & Log & $\begin{array}{l}2702.29 \\
5\end{array}$ & $\begin{array}{l}2717.11 \\
6\end{array}$ & 0 & Y \\
\hline $\begin{array}{l}\text { Model } \\
2\end{array}$ & Gamma & Log & $\begin{array}{l}2713.47 \\
7\end{array}$ & $\begin{array}{l}2723.36 \\
2\end{array}$ & 0 & N \\
\hline
\end{tabular}

\begin{tabular}{|l|l|l|l|l|l|l|}
\hline $\begin{array}{l}\text { Model } \\
3\end{array}$ & Normal & Identity & $\begin{array}{l}2845.32 \\
9\end{array}$ & 2860.15 & 0 & Y \\
\hline $\begin{array}{l}\text { Model } \\
4\end{array}$ & Normal & Identity & $\begin{array}{l}2861.55 \\
5\end{array}$ & $\begin{array}{l}2871.43 \\
9\end{array}$ & 0 & N \\
\hline $\begin{array}{l}\text { Model } \\
5\end{array}$ & Normal & Log & $\begin{array}{l}3723.60 \\
1\end{array}$ & $\begin{array}{l}3738.42 \\
2\end{array}$ & 0 & Y \\
\hline $\begin{array}{l}\text { Model } \\
6\end{array}$ & Normal & Log & $\begin{array}{l}3898.31 \\
4\end{array}$ & $\begin{array}{l}3908.19 \\
9\end{array}$ & 0 & N \\
\hline 1 & & &
\end{tabular}

Table 3: Information criteria of models in which different error distributions and link functions were combined.

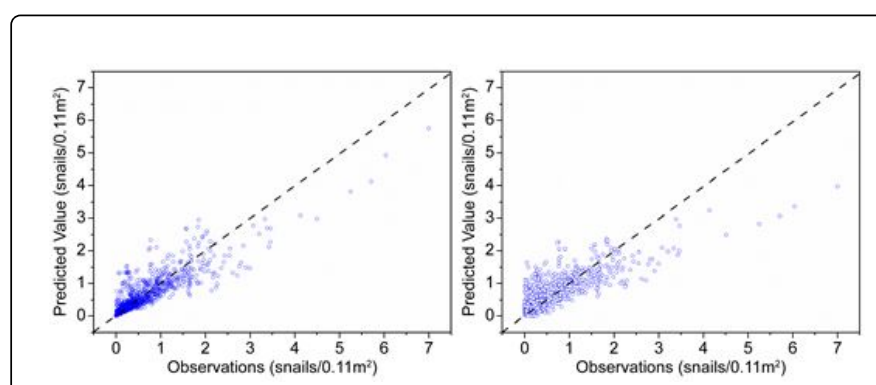

Figure 4: Scatter plots of predicted versus observed values of snail density between models 1 and 3 .

\begin{tabular}{|l|l|l|l|l|}
\hline & \multicolumn{2}{|l}{ Model 1 } & Model 2 \\
\hline Variables & Coefficient & p-value & Coefficient & p-value \\
\hline Intercept & -7.507 & 0 & -5.478 & 0 \\
\hline Precipitation & 0.021 & 0 & 0.015 & 0 \\
\hline Daylight hours & 0.015 & 0 & 0.01 & 0 \\
\hline NDVI & -1.025 & 0.013 & -10.73 & 0.015 \\
\hline LST & 0.015 & 0.028 & 0.009 & 0.215 \\
\hline WI & 2.342 & 0.013 & 2.218 & 0.028 \\
\hline DEM & -0.003 & 0 & -0.004 & 0 \\
\hline Silt proportion & 0.079 & 0.002 & 0.068 & 0.014 \\
\hline Near_dis & 0.01 & 0.721 & 0.008 & 0.8 \\
\hline
\end{tabular}

Table 4: Estimated parameters of the fixed variables of the models.

All the tested environmental factors that previous studies and schistosomiasis projects identified as potentially influencing snail density were included in the model. Table 4 shows the estimated parameters of the variables associated with snail density that were determined using model 1 (gamma distribution and a logarithmic link 
function), in which the effect of time was considered as a random effect. The results of model 2 (in which the effect of time was not considered) are presented in Table 4 for comparison. In model 1, the intercept and year were random effects; in model 2, only the intercept was the random effect. The coefficients of the models showed the relationship between each variable and snail density. Model 1 included the following statistically significant variables $(\mathrm{p}<0.05)$ : precipitation, daylight hours, NDVI, LST, WI, DEM, and silt proportion. The distance to the nearest water body was not statistically significant. Precipitation, daylight hours, LST, WI, and silt proportion were positively related to snail density, with regression coefficients of 0.021 , $0.015,0.015,2.342$, and 0.079 , respectively. By contrast, NDVI and DEM were negatively associated with snail density, with regression coefficients of -1.025 and -0.003 , respectively. However, the variance in the residual and random effects was statistically significant $(\mathrm{p}<0.001)$ after the model was fitted. LST was not statistically significant when model 2 was established, using only the intercept as the random effect. The significance levels of NDVI, WI, and soil proportion in model 2 were higher than those in model 1 ; however, the regression coefficient values of the significant variables in model 2 were less than those in model 1.

The standardized variables showed that the coefficients of the environmental factors were $0.528,0.109,-0.260,0.182,0.025,-0.171$, and 0.213 , respectively. The impact of the environmental factors on variation in snail density was ranked as follows: precipitation $>$ silt proportion $>$ LST $>$ daylight hours $>$ WI $>$ DEM $>$ NDVI. Thus, precipitation had the greatest effect on snail density, while NDVI had the lowest effect.

\section{Discussion}

At present, the breeding habitats of $O$. hupensis snails are being transformed from lakes and marshlands to water networks in the Jianghan Plain. Irrigation and drainage networks are already wellestablished, with rivers connecting to canals, which connect to ditches, which further connect to the ponds and fields surrounding the villages. Snails are primarily distributed along rivers but spread through canals and ditches to paddy fields. Considering the current situation of snail distribution, understanding the occurrence rates of areas harboring snails by analyzing the dynamic tendency of snail distribution is essential.

In this study, we found that the number of villages with $<50 \%$ occurrence rates of snail-infested areas was more than $70 \%$, while $0 \%$ occurrence rates of areas with snails was found in $>30 \%$ villages. This highlights the fact that attention should be paid to the areas with snail occurrence rates of $1 \%$ to $50 \%$ to manage snail habitats. Therefore, these findings might indicate the basis for monitoring and controlling snail populations in future.

We found that villages with higher occurrence rates of snailcontaining areas were discrete from 2008 to 2012, with the number of such villages declining over time. This result might partly be due to the effect of countermeasures implemented over the five-year study period. Our results also showed that the number and percentage of villages with higher occurrence rates of snail-infested areas significantly declined in the study area in 2011. This might be attributed to the extreme drought in the winter of 2010 and spring of 2011. In 2012, the number and percentage of villages with a higher occurrence rate of snail-containing areas increased again. Thus, efforts to achieve complete control of snail populations and to prevent their growth in such areas must be strengthened.

In the investigations of the spatial dynamics of snails and the identification of environmental factors influencing snail density, the following statistically significant variables $(p<0.05)$ were identified: precipitation, daylight hours, NDVI, LST, WI, DEM, and silt proportion. The distance to the nearest water body was not statistically significant. With regard to the impact level, the environmental factors affecting variation in snail density could be ranked as follows: precipitation $>$ silt proportion $>$ LST $>$ daylight hours $>$ WI $>$ DEM $>$ NDVI. Thus, precipitation elicited the greatest effect on snail density, and NDVI had the lowest effect. Clarifying the relationship between environmental factors and snail density will enable drawing out plans and strategies for snail control.

By improving our knowledge of the spatio-temporal distribution of snails and the associated environmental factors, it might be possible to establish a scientific basis on which to develop effective strategies to control and prevent schistosomiasis occurrence [12,26,27]. Investigations on the spatial dynamics of snails and the identification of factors influencing snail density have been previously attempted by combining the $3 \mathrm{~S}$ technology, namely, GIS/RS/GPS with statistical models, such as GLMs [10], Bayesian models [14,26], and multiple logistic regression models $[12,13]$. However, previous approaches used data obtained within a single year; thus, the effects of time on snail distribution were not considered.

It is possible to control and prevent outbreaks of $S$. japonica effectively by eradicating snails through environmental modification and molluscicide application. Therefore, variation in the spatiotemporal distribution of snail-infested areas in different regions should be accurately described, and environmental factors associated with snail habitats should be evaluated through a combination of descriptive analysis and statistical methods.

The selection of a good statistical method might help provide a scientific basis to indicate the relationship between snail density and the environmental habitat in which they are found. The results of such analyses could also help predict future occurrences of local schistosomiasis epidemics. However, the effect of time has been rarely considered in previous studies. The GLMM used in the current study demonstrated that time has a major effect on the relationship between snail density and associated environmental factors. For instance, model 1 , which considered the intercept and year as random effects, was superior to model 2, which only considered the intercept as the random effect. This finding further confirms the superiority of the model with the random effect. The structuring of the random effect has a decisive function on the significance and interpretation of fixed effects. Thus, adding random effects to the modelling procedure is as important as the selection of fixed effects. Year was specified as a random effect, and temporal correlation was applied to the modelling. One of the main advantages of GLMMs is that they may be extended to incorporate additional data specified as random effects [28]. Therefore, GLMMs are a preferred tool for identifying the risk factors of snail distribution.

In this study, model 1 identified environmental factors that were significantly associated with snail density. Humidity and vegetation coverage represent two key environmental factors affecting snail density at a small scale $[6,29]$. Our results revealed that WI positively affected snail density, whereas NDVI had a negative effect. This finding suggests that geographical environments with high WI and appropriate 
NDVI provide favorable habitats for snails. However, this result is inconsistent with those of some earlier studies [7,9,30], possibly because the study scale in the GLMM was the administrative village, belonging to a mesoscale environment. NDVI ranges from -1 to +1 , with negative value corresponding to water bodies or snow. As the value approaches +1 , vegetation cover increases. At a large scale (e.g., county or province or larger), an increase in NDVI indicates the presence of suitable snail habitat. In comparison, at a small scale (such as a village), a low NDVI and a high WI suggest the presence of water: thus, suitable snail habitats are likely to be present [11]. Hence, different study scales might affect the indicative function of the same environmental factor.

Besides WI and NDVI, our study showed that other variables also contributed to the survival of snails. After standardizing the environmental factors, the positive effect of the average precipitation from March to May had the greatest effect among all studied factors. Precipitation was the direct natural cause of changes to the other environmental factors associated with snail density. For example, precipitation directly adds water to soil, creating wet conditions for snail breeding. Precipitation also affects vegetation growth, thereby indirectly influencing soil factors [31]. Under these conditions, the range of schistosomiasis endemic areas can spread. Snail density was positively correlated with the proportion of silt and LST, supporting the findings of previous studies [32,33]. The average number of hours of daylight is fairly consistent from March to May in our study area, with this environmental factor being positively correlated with snail density. Our findings showed that snail density was negatively correlated with DEM, supporting a previous study showing that snails inhabited areas with relatively low elevation [34]. As the DEM is low and remains unchanged over the Jianghan Plain, it had a relatively small influence on snail density. The effect of distance to the nearest water source was not statistically significant, possibly because of the dense river system in the Jianghan Plain, which might decrease the importance of this explanatory variable.

This study had various limitations, which should be addressed in future research. First, the interactions between environmental factors and snail density are complex. Several environmental variables, such as the water table, soil $\mathrm{pH}$, and soil organic matter content, were not incorporated into the model as explanatory variables because of the difficulties associated with collecting long time-series data. Moreover, not all possible factors associated with snail distribution were considered in our models. Second, snail density and the corresponding environmental factors were obtained as mean values at the village level because the exact coordinates were not recorded in the historical data of the snails. This procedure might have influenced our results to a certain extent. Third, the impact of the spatial effects on snail density was not considered in our GLMM because of the complexity of timespace interactions, and should be incorporated in future research. Under the project supported by the National Science Foundation, our research group will continue to collect snail data at a small scale within this area to facilitate the development of integrated models accounting for the effects of time, space, and space-time interactions. This approach is expected to allow the accurate identification of environmental factors, from which snail density can be predicted for use in mitigation programs.

\section{Conclusions}

In this study, GIS, RS, descriptive analysis, and statistical methods were employed to investigate the spatial dynamics of the occurrence rate of snail-infested areas and to identify the environmental factors influencing snail density at a large scale in the Jianghan Plain, China. By using six models, we showed that eight environmental factors influenced snail density and distribution, with model 1 being the most representative. As a result, a spatio-temporal distribution model was formulated in this study. Precipitation had the highest impact on variation in snail density, and NDVI had the lowest impact. Our present findings can be used as a theoretical basis to develop models predicting snail distribution in the Jianghan Plain for use in the prevention and control of schistosomiasis.

\section{Acknowledgments}

This research was supported by the National Natural Science Foundation of China (Grant No.: 41571487), National Science and Technology Support Plan (Grant No.: 2009BAI78B03), Special Fund for Climate Change of CMA (No. CCSF201409), and National Science and Technology Major Projects (No. 2012ZX10004909).

\section{Author Contributions}

Y.Y. has contributed to draft the work and to participate the acquisition and analysis of data for the work. B.C. has contributed to draft the work; to participate the acquisition and analysis of data for the work. J.Q. has contributed to the acquisition and analysis as well as the interpretation of data for the work. K.L. has contributed to the acquisition and analysis of climate data for the work. X.X. has contributed to the conception of the work and to be accountable for all aspects of the work and final approval of the version to be published. R.L. has contributed to the conception and design of the work and to be accountable for all aspects of the work and final approval of the version to be published.

\section{Conflicts of Interest}

The authors declare no conflict of interest.

\section{References}

1. Ross AGP, Sleigh AC, Li YS, Davis GM, Williams GM, et al. (2001) Schistosomiasis in the People's Republic of China: Prospects and challenges for the 21st century. Clin Microbiol Rev 14: 270-295.

2. Chen XY, Wang LY, Cai JM, Zhou XN, Zheng J, et al. (2005) Schistosomiasis control in China: The impact of a 10-year World Bank Loan Project (1992-2001). Bull World Health Organ 83: 43-48.

3. Zhou XN, Wang LY, Chen MG, Wu XH, Jiang QW, et al. (2005) The public health significance and control of Schistosomiasis in China-then and now. Acta Tropica 96: 97-105.

4. Colley DG, Bustinduy AL, Secor WE, King CH (2006) Human schistosomiasis. Lancet 383: 2253-2264.

5. Zhou XN, Wang TP, Wang LY, Guo JG, Yu Q, et al. (2004) The current status of Schistosomiasis epidemics in China. Zhonghua Liu Xing Bing Xue Za Zhi 25: 555-558.

6. Bavia ME, Malone JB, Hale L, Dantas A, Marronim L, et al. (2001) Use of thermal and vegetation index data from earth observing satellites to evaluate the risk of schistosomiasis in Bahia, Brazil. Acta Tropica 9: 79-85.

7. Kristensen TK, Malone JB, McCarroll JC (2001) Use of satellite remote sensing and geographic information systems to model the distribution and abundance of snail intermediate hosts in Africa: A preliminary model for Biomphalaria pfeifferi in Ethiopia. Acta Tropica 79: 73-78.

8. Guo JG, Vounatsou P, Cao CL, Utzinger J, Zhu HQ, et al. (2005) A geographic information and remote sensing based model for prediction 
Citation: Yuan Y, Chang B, Qiu J, Liu K, Xu X, et al. (2018) Environmental Factors Influencing the Distribution of Oncomelania hupensis in Central Region, China. J Trop Dis 6: 270. doi: 10.4172/2329-891X.1000270

Page 8 of 8

of Oncomelania hupensis habitats in the Poyang Lake area, China. Acta Tropica 96: 213-222

9. Zhang ZY, Xu DZ, Zhou XN, Zhou Y, Liu SJ (2005) Remote sensing and spatial statistical analysis to predict the distribution of Oncomelania hupensis in the marshlands of China. Acta Tropica 96: 205-212.

10. Zhang Z, Ong SH, Peng WX, Zhou YB, Zhuang JL, et al. (2008) A model for the prediction of Oncomelania hupensis in the lake and marshland regions, China. Parasitol Int 57: 121-131.

11. Yang K, Zhou XN, Wu XH, Steinmann P, Wang XH, et al. (2009) Landscape pattern analysis and Bayesian modeling for predicting Oncomelania hupensis distribution in Eryuan County, People's Republic of China. Am J Trop Med Hyg 81: 416-423.

12. Hu Y, Zhang ZJ, Chen Y, Wang ZL, Gao J, et al. (2013) Spatial pattern of schistosomiasis in Xingzi, Jiangxi Province, China: The effects of environmental factors. Parasit Vectors 6: 214

13. Qiu J, Li RD, Xu XJ, Yu CH, Xia X, et al. (2014) Identifying determinants of Oncomelania hupensis habitats and assessing the effects of environmental control strategies in the plain regions with the waterway network of China at the microscale. Int J Environ Res Publ Health 11: 6571-6585.

14. Yang GJ, Vounatsou P, Zhou XN, Tanner M, Utzinger J (2005) A Bayesian-based approach for spatio-temporal modeling of county level prevalence of Schistosoma japonicum infection in Jiangsu province China. Int J Parasitol 35: 155-162.

15. Zhang ZJ, Bergquist R, Chen DM, Yao BD, Wang ZL, et al. (2013) Identification of parasite-host habitats in Anxiang County Hunan Province China based on multi-temporal China-Brazil Earth Resources Satellite (CBERS) images. PLOS ONE 8: e69447.

16. Goovaerts P (2000) Geostatistical approaches for incorporating elevation into the spatial interpolation of rainfall. J Hydrol 228: 113-129.

17. GloVis USGS Available online: http://glovis.usgs.gov//

18. Qin ZH, Li WJ, Xu B, Chen ZX, Liu J (2006) The estimation of land surface emissivity for landsat TM6. Remote Sensing Land Resour 16: 28-32.

19. Sobrino JA, Jimenez-Munoz JC, Paolini L (2004) Land surface temperature retrieval from LANDSAT TM 5. Remote Sensing Environ 90: 434-440.

20. Gamerman D (1997) Sampling from the posterior distribution in generalized linear mixed models. Stat Comput 7: 57-68.

21. Littell RC, Pendergast J, Natarajan R (2000) Modelling covariance structure in the analysis of repeated measures data. Stat Med 19: 1793-1819.
22. Dean CB, Nielsen JD (2007) Generalized linear mixed models: a review and some extensions. Lifetime Data Anal 13: 497-512.

23. Cavanaugh JE (1997) Unifying the derivations for the Akaike and corrected Akaike information criteria. Stat Probabil Lett 33: 201-208.

24. Kutner MH, Nachtsheim C, Neter J (2004) Applied Linear Regression Models McGraw-Hill/Irwin New York, US 193-369.

25. Spiegelhalter DJ, Best NG, Carlin BR, van der Linde A (2002) Bayesian measures of model complexity and fit. J R Stat Soc Series B Stat Methodol 64: 583-616.

26. Yang K, Wang XH, Yang GJ, Wu XH, Qi YL, et al. (2008) An integrated approach to identify distribution of Oncomelania hupensis the intermediate host of Schistosoma japonicum in a mountainous region in China. Int J Parasitol 38: 1007-1016.

27. Zhang ZJ, Clark AB, Bivand R, Chen Y, Carpenter TE, et al. (2009) Nonparametric spatial analysis to detect high-risk regions for schistosomiasis in Guichi China. Trans R Soc Trop Med Hyg 103: 1045-1052.

28. Kleinschmidt I, Sharp BL, Clarke GPY, Curtis B, Fraser C (2001) Use of generalized linear mixed models in the spatial analysis of small-area malaria incidence rates in KwaZulu Natal South Africa. Am J Epidemiol 153: 1213-1221.

29. Zealand AM, Jeffries MJ (2009) The distribution of pond snail communities across a landscape: separating out the influence of spatial position from local habitat quality for ponds in south-east Northumberland UK. Hydrobiologia 632: 177-187.

30. Zhao A, Bao S, Gong P (2009) Using weights of evidence in the spatial relation between infected snails and geographic factors. Geo-spatial Info Sci 12: 217-224.

31. Liu NW (2000) Physical Geography. Science Press Beijing China 235-298.

32. Zhang ZY, Sun ZD, Xu DZ, Zhou Y, Gong ZL, et al. (2004) Analysis on the environmental features for the distribution of Oncomelania snails in Jiangning county by the geographic information system. Chinese J Dis Control Prevention 8: 16-18.

33. He ZY, Lin DD, Zhu R, Gong P, Guo JG (2006) Effects of land surface temperature on supervising the existing area if snails. Chinese $\mathrm{J}$ Preventive Med 40: 234-238.

34. Zhou XN (2005) Science of Oncomelania Snail. Science Press Beijing China 158-166. 